\title{
PSICOLOGIA SOCIAL E CRAS: A EXPERIÊNCIA DE UMA OFICINA DE FOTOGRAFIA COMO DISPOSITIVO RESSIGNIFICADOR DE SENTIDOS
}

SOCIAL PSYCHOLOGY AND CRAS: THE EXPERIENCE OF A PHOTOGRAPHY WORKSHOP AS A RESIGNER DEVICE OF SENSES

PSICOLOGÍA SOCIAL Y "CRAS": LA EXPERIENCIA DE UNA OFICINA DE FOTOGRAFÍA COMO DISPOSITIVO RESIGNIFICADOR DE SENTIDOS

\author{
Mariá Boeira Lodetti \\ Yasmin Sauer Machado ${ }^{* *}$ \\ Kátia Maheirie ${ }^{* * *}$ \\ Flora Lorena Branco Müller ${ }^{* * * *}$ \\ Caio Cezar Nascimento ${ }^{* * * *}$
}

\begin{abstract}
RESUMO
Este trabalho compartilha a experiência de uma oficina realizada com jovens, em um Centro de Referência em Assistência Social (CRAS) da cidade de Florianópolis (Brasil), durante o ano de 2013. As oficinas tiveram como foco a linguagem fotográfica, a qual pôde fazer-se mediadora dos processos de significação e ressignificação dos sujeitos em relação ao território. As oficinas envolveram a apropriação de técnicas fotográficas e a discussão de questóes ligadas à relação dos participantes com o território. As informações, examinadas por meio da análise de conteúdo, foram produzidas via observaçóes registradas em diário de campo, material publicado em redes sociais e entrevistas com os sujeitos ao fim dos encontros da oficina. Os resultados apontam que a linguagem fotográfica se coloca como mediadora na criação de espaços de reflexão acerca de si e de seu contexto, estabelecendo relações capazes de aumentar suas potências de vida e de ampliação de perspectivas de futuro.
\end{abstract}

Palavras-chave: CRAS. Fotografia. Oficinas.

\footnotetext{
Texto recebido em 3 de abril de 2014 e aprovado para publicação em 12 de novembro de 2015.

Mestranda em Psicologia pela Universidade Federal de Santa Catarina (UFSC), Florianópolis-SC, Brasil. E-mail: mboeiralodetti@ gmail.com.

* Graduada em Psicologia pela UFSC. E-mail: yasminsm@gmail.com.

*** Doutora em Psicologia Social pela PUC-SP, professora associada do Departamento e do Programa de Pós-Graduação na UFSC, pesquisadora do CNPq. E-mail: maheirie@gmail.com.

${ }^{* * *+*}$ Mestra em Psicologia Social pela UFSC. E-mail: floramuller@gmail.com.

${ }^{* * * * *}$ Fotógrafo profissional. Endereço: Departamento de Psicologia- Campus Universitário Reitor João David Lima. Trindade, Florianópolis-SC, Brasil. CEP: 88040-900. E-mail: caiocezarfotografia@gmail.com.
} 


\section{ABSTRACT}

This work shares the experience of a workshop held with young people, in a Social Assistance Reference Center (CRAS) in the city of Florianópolis (Brazil), during the year 2013. The workshops focused on the photographic language, which can mediate the processes of signification and resignification of the subjects in regard with the territory. The workshops involved the appropriation of photographic techniques and the discussion of issues related to the relation of the participants with the territory. The information, analyzed through content analysis, was produced through observations recorded in field diary, material published in social networks and interviews with the subjects at the end of the workshop meetings. The results show that the photographic language is a mediator in the creation of spaces for reflection about oneself and its context, establishing relationships capable of increasing their potencies of life and expanding future perspectives.

Keywords: CRAS. Photography. Workshops.

\section{RESUMEN}

Este trabajo comparte la experiencia de un taller realizado con jóvenes, en un Centro de Referencia en Asistencia Social (CRAS) de la ciudad de Florianópolis (Brasil), durante el año 2013. Los talleres tuvieron como foco el lenguaje fotográfico, el cual puede actuar como mediador de los procesos de significación y resignificación de los sujetos en relación al territorio. Los talleres involucraron la apropiación de técnicas fotográficas y la discusión de cuestiones vinculadas a la relación de los participantes con el territorio. Las informaciones, estudiadas por medio del análisis de contenido, fueron producidas a través de observaciones registradas en diario de campo, material publicado en redes sociales y entrevistas con los sujetos al final de los encuentros del taller. Los resultados muestran que el lenguaje fotográfico se coloca como mediador en la creación de espacios de reflexión acerca de sí y de su contexto, estableciendo relaciones capaces de aumentar sus potencias no sólo de vida sino también de ampliación de perspectivas de futuro.

Palabras clave: CRAS. Fotografia. Taller.

\section{INTRODUÇÃO}

A política de Assistência Social, que deu origem à criação do Sistema Único de Assistência Social (SUAS) e, consequentemente, ao Centro de IReferência de Assistência Social (CRAS), tem, em sua equipe profissional, um importante espaço de atuação para o psicólogo. As possibilidades de atuação ainda são muito discutidas, tanto na produção acadêmica quanto na formação e prática cotidiana dos profissionais. $\mathrm{O}$ trabalho interdisciplinar está no princípio 
de toda intervenção realizada pelo CRAS, uma vez que deve ser realizado por uma equipe e seu objeto de trabalho é extremamente complexo e multifacetado, requerendo competência e propensão de diversos profissionais que atuem juntos em torno de um objetivo em comum: apoiar e fortalecer vínculos entre sujeitos (Brasil, 2009). Nas diretrizes e manuais norteadores do trabalho prático do CRAS, observa-se a necessidade do oferecimento de atividades que propiciem o convívio comunitário aos usuários, de modo a fortalecer seus vínculos e a prevenir situaçôes de vulnerabilidade e de risco (Brasil, 2012).

O problema central do trabalho que ora apresentamos é entender de que forma a unificação da linguagem imagética, especialmente a fotografia, a práticas que visem ao trabalho coletivo nos CRAS pode potencializar o fortalecimento de vínculos entre sujeitos em determinado território. Para tanto oferecemos uma oficina de fotografia contando com um fotógrafo profissional em nossa equipe, de forma a possibilitar a apropriação de técnicas específicas a linguagem fotográfica, oportunizando alternativas de trabalho àqueles jovens.

O CRAS em que se realizou a oficina de fotografia localiza-se na cidade de Florianópolis, Estado de Santa Catarina. A unidade atende cerca de 1040 famílias cadastradas em um território composto por seis bairros daquela cidade. A sede do CRAS assenta-se em um desses bairros, mas o espaço em que se efetivou a oficina de fotografia foi uma escola da rede pública, em outro bairro. Dessa forma, a condução de alguns participantes e dos oficineiros ocorreu pelo carro da Secretaria de Assistência Social, que é disponibilizado para este CRAS em dois turnos, durante a semana.

No contemporâneo, as facilidades em se obter instrumentos capazes de registrar os cenários da vida cotidiana fizeram do campo das imagens um importante meio de mediação entre a subjetividade humana e a vida social (Pino, 2006). Quando se fala então desse uso na área da Psicologia, observa-se que a fotografia tem a capacidade de gerar um campo de inquietações, questionamentos e reflexões, uma vez que uma imagem pode ter diversas interpretações, servindo como dispositivo para os sujeitos se expressarem verbalmente (Maheirie, Boing, \& Pinto, 2005; Maurente \& Tittoni, 2007; Müller, 2013; Neiva-Silva \& Koller, 2002; Souza, 2006; Strappazzon, Santa, Werner, \& Maheirie, 2008; Zanella \& Tittoni, 2011). Fala-se então da possibilidade criativa do sujeito e, consequentemente, das relações estéticas que estabelece com o mundo (Maheirie, Muller, Gomes, Gomes, \& Hinkel, 2011; Maheirie et al., 2012; Müller, 2013; Zanella, 2010).

Dessa forma, é conveniente pensar que uma oficina de fotografia com jovens (oferecida por uma instituição que tem em seus princípios o fortalecimento dos vínculos comunitários) pode representar um importante dispositivo ressignificador de sentidos. 
Em decorrência das reflexões aqui apontadas, procura-se, neste artigo, discorrer sobre a experiência de uma oficina de fotografia realizada com jovens e em parceria do CRAS com uma escola da rede pública de Florianópolis, compartilhando uma possibilidade de trabalho para o psicólogo no CRAS.

\section{O CRAS E O SUAS}

O SUAS teve sua criação bastante recente no Brasil. Sua gênese nos remete à Constituição de 1988, quando foram assegurados os direitos relativos ao triângulo saúde, assistência e previdência social, graças à pressão e luta de movimentos sociais (Oliveira, Dantas, Sólon, \& Amorim, 2011; Yamamoto \& Oliveira, 2014). Em 1993, por meio da Lei Orgânica da Assistência Social (LOAS) (Lei $n^{\circ} 8.742 / 1993$ ), pela primeira vez, a assistência social foi reconhecida como um direito do cidadão e dever do Estado, garantindo-se proteção social à segurança de sobrevivência, de acolhida e de convívio familiar (Brasil, 2005).

A Política Nacional de Assistência Social como política social de enfrentamento às desigualdades socioterritoriais surgiu em 2004. Em 2005, aprovado pela Resolução no 145 do Conselho Nacional de Assistência Social (CNAS), pela Política Nacional de Assistência Social (PNAS) e pela Norma Operacional Básica (NOB/SUAS), nasceu o SUAS, como forma de garantir, por meio de políticas públicas, o direito à seguridade e à proteção social básica aos cidadãos brasileiros (Silva \& Corgozinho, 2011). Dividido entre três níveis de complexidade (proteção social básica, proteção social especial e proteção social especial de alta complexidade), o SUAS destina-se àqueles cidadãos que estão em situação de vulnerabilidade e riscos. Assim, o SUAS compreende essa situação consumada por perda ou fragilidade de vínculos afetivos; por ciclo de vida; por termos étnicos, culturais e sexuais; por alguma deficiência; por exclusão resultante de pobreza ou de falta de acesso às políticas públicas; por uso de substâncias que causam dependência; por violência familiar ou urbana; por inserção insuficiente no mercado de trabalho; por outros tipos de situações de sobrevivência que apresentam como consequência um risco ao indivíduo (Brasil, 2005).

Sob esse aspecto, é importante destacar que há diferenças entre risco e vulnerabilidade. No risco, há uma noção de perigo, como o risco de um acontecimento displicente, ou uma noção de probabilidade, ou o risco como uma chance de ganho ou perda. Já a vulnerabilidade é entendida como um conceito que complementa o conceito de risco, que não está diretamente ligado à possibilidade de um acontecimento futuro, como uma ideia de porvir, mas está ligado a uma condição mais constante em que o sujeito se encontra, na qual pode haver uma relação entre diferentes tipos de riscos. 
Paralela às noções de risco e vulnerabilidade, é importante destacar a noção de território que a Política de Assistência Social referencia: território como mensurador de situações sociais. Ou seja, disserta a compreensão de território como um contexto no qual o sujeito está inserido, com suas potencialidades e fragilidades que tornam possível uma análise de risco e de vulnerabilidade; um contexto que pode ser propiciador de relações entre diferentes instituições, as quais têm potencialidade de formar redes, a fim de que riscos e vulnerabilidades possam ser superados (Brasil, 2005).

O CRAS situa suas atividades dentro da proteção social básica. Constituise na unidade pública estatal de base territorial, a qual se encontra em regiōes de vulnerabilidade social e consiste na porta de entrada do SUAS. Os serviços oferecidos pelos CRAS buscam o fortalecimento de vínculos familiares e comunitários, e a ampliação do acesso aos direitos de cidadania (Brasil, 2009).

A atuação do CRAS ocorre diretamente com famílias e indivíduos no respectivo contexto comunitário, assumindo como fatores identitários a matricialidade sociofamiliar (a família enquanto núcleo social básico das ações e serviços das políticas) e a territorialização (o território como determinante para a compreensão e enfrentamento de vulnerabilidade e risco social) (Brasil, 2009). O principal serviço oferecido é o Programa de Atenção Integral às Famílias (PAIF), cujo objetivo consiste na orientação e no convívio sociofamiliar e comunitário (Brasil, 2009).

Em 2008, o Conselho Federal de Psicologia elaborou um documento com referências técnicas para a atuação do psicólogo no CRAS, no qual sanciona que o trabalho desse profissional deve ser baseado em açôes interdisciplinares, cuja finalidade consiste em fundamentar investigaçôes acerca das situações do território de referência de cada de CRAS.

O psicólogo deve integrar as equipes de trabalho em igualdade de condições e com liberdade de ação, num papel de contribuição nesse processo de construção de uma nova ótica da promoção, que abandona o assistencialismo, as benesses, que não está centrada na caridade e nem favor, rompendo com o paradigma da tutela, das ações dispersas e pontuais (Centro de Referência Técnica em Psicologia e Políticas públicas [Crepop], 2008, p. 33).

Toda política da assistência social está fundamentada nas garantias sociais, as quais conduzem ações que objetivam assegurar a efetivação dos direitos sociais homologados pelo Estado brasileiro. Entre essas formas de garantias sociais, encontra-se a acolhida, o convívio familiar e comunitário e o desenvolvimento da autonomia. Destaca-se aqui que o convívio familiar e comunitário pode se 
basear em vivências que colaboram para o fortalecimento de vínculos familiares e comunitários, em que os sujeitos possam reconhecer possibilidades que lhes empoderem como sujeitos de sua história, possibilitando uma maior compreensão de seu território, uma maior participação social (Brasil, 2012).

Durante o curso de vida, no contexto da cultura ocidental e urbana, algumas características comuns evidenciam-se entre os jovens, como mudanças nas significações e sentidos que produzem acerca de si e do mundo. Nessa perspectiva, Besset, Coutinho, e Cohen (2008) afirmam que a troca entre os jovens é um recurso importante para a superação das demandas paradoxais (entre a infância e a vida adulta). Os grupos, dessa forma, fazem o sujeito sentirse em pertencimento a um coletivo, como "uma turma", propiciando novas experiências de ressignificação do mundo e superando as tensões e ansiedades desse momento de vida. Paralelamente, pode-se pensar que os grupos podem ser propiciadores do que Sawaia (2001), inspirada em Espinosa, conceitua de "bons encontros": quando pessoas, a partir dos encontros concretos entre os corpos, tem sua potência de vida aumentada.

Nos últimos dez anos, houve uma ampliação da inserção do psicólogo nas políticas públicas e, aliado a isso, é possível afirmar que diferentes experiências foram proporcionandodiversificadas práticas no enfrentamento davulnerabilidade (Alberto, Freire, Leite, \& Gouveia, 2014). Paralelamente, muitas publicaçôes recentes problematizam práticas, lugares e saberes, apontando alternativas e processos de criação de novos fazeres no cenário da Psicologia (Andrade \& Romagnoli, 2010; Cruz \& Guareschi, 2009; Reis \& Cabreira, 2013; Senra \& Guzzo, 2012, entre outras). Entre as diferentes possibilidades de atuação no psicólogo nesses centros de referência e com base em trabalhos potentes com oficinas em contextos de periferia (Müller, 2013; Strappazzon et al., 2008; Titon, 2008), entendemos que a oferta de oficinas de fotografia para jovens pode promover o convívio comunitário, a construção de laços intersubjetivos e, ou, grupais, assim como o fortalecimento de si como sujeito.

\section{A FOTOGRAFIA COMO DISPOSITIVO}

As produções tecnológicas de todas as épocas são dispositivos que repercutem sobre a subjetividade humana como importantes mediadoras nas estratégias de intervenção psicossocial (Strappazzon et al., 2008). As novas tecnologias da informática e da comunicação trouxeram imagens aos diversos espaços públicos da vida social, de forma a adentrar no mundo da subjetividade e ameaçar tomar conta da intimidade da vida privada das pessoas (Pino, 2006). Na pesquisa e no ensino, é interessante observar que a fotografia se constitui como dinâmica 
de intervenção, incluindo tanto o gesto daquele que fotografa quanto o olhar de quem lê a foto, tendo em vista que ambos remetem a operaçôes criadoras de pensamento (Souza, 2006). Segundo Souza (2006), mais do que retratar, a fotografia permite observar a influência de registros de memória, modificando a relação entre o sujeito e o mundo.

Para Maheirie (2002), todo processo de construção do sujeito é realizado no coletivo e, inserido nesse cenário de múltiplas singularidades que se entrecruzam, ele realiza a sua história e a dos outros, na mesma medida em que é realizado por ela: produto e produtor, simultaneamente.

Constituir-se como sujeito consiste em realizar a dialética do objetivo e do subjetivo, uma vez que o sujeito existe como subjetividade objetivada: que pela subjetividade (negação) se objetiva novamente, encontrando, por meio da subjetividade (negação), uma nova objetivação, e assim infinitamente (Maheirie, 2002, p. 37).

A autora afirma que os conceitos de sujeito e subjetividade não podem ser sinônimos, tendo em vista que a subjetividade (assim como a objetividade) é compreendida como uma dimensão do sujeito. Essas duas dimensões relacionadas dialeticamente no contexto social produzem o que entendemos por sujeito, na perspectiva de um ser aberto, inacabado e em constante devir, ou seja, o sujeito é um constante criar e recriar(-se).

Segundo Vigotsky (2003), atividade criadora é qualquer tipo de atividade em que o ser humano cria algo novo, que pode ser tanto um produto da objetividade quanto do que chamamos de modos de subjetivação, como a criação e organização de pensamentos, sentimentos, os quais se objetivam em formas de agir no mundo. Quando o ser humano imagina um fato do passado, ele nunca reproduz as mesmas impressóes que uma vez experimentou: criamse novas imagens, novas ações, novas ideias. $\mathrm{O}$ cérebro não apenas conserva $\mathrm{e}$ reproduz a experiência anterior, ele também combina, transforma e cria com base nos elementos de uma experiência anterior. Portanto, "processos de criação implicam sempre em movimentos de subjetivação e objetivação de sujeitos" (Strappazzon et. al., 2008, p. 5), os quais se constituem a partir da linguagem, na relação semiótica que se estabelece com o outro.

De acordo com Zanella et al. (2006), ao destacar a possibilidade criativa do sujeito, estamos necessariamente falando de novas experiências estéticas, ou seja, das relações de estranhamento de sentidos cristalizados que consegue estabelecer em sua experiência. O estético está ligado aos órgãos do sentido (ouvir, ver, pensar, experimentar), ou seja, é um processo de sensibilização da vida cotidiana, 
problematizando-a em seu caráter hegemônico. Assim, a relação estética pode ser compreendida como o processo que vai superar a viciosidade do mundo, que vai criar e recriar sentido: é a possibilidade de sentir o mundo e produzir novos sentidos sobre si mesmo, é um encontro que provoca uma reflexão (Strappazzon, 2011).

A relação estética é um conceito que chama atenção para a qualidade dos encontros com o outro, marcado por um posicionamento afetivo, cognitivo e sensível. São relações essenciais para a compreensão e leitura das diversas faces da realidade, para o entendimento das múltiplas alternativas de existência individual e grupal (Zanella, 2010). Entretanto não é qualquer relação do ser humano consigo mesmo ou com seu entorno que pode ser caracterizada como uma relação estética. Para que aconteça, é preciso estranhar o comum, aquilo que já dado e estabelecido no universo predominantemente prático-utilitário. É preciso desconstruí-lo e, apesar de não indicar uma ação em si, prepara-a para ela, por meio de novas formas de sentir e pensar.

De acordo com Neiva-Silva \& Koller (2002), atribuir significados à imagem é o que se objetiva ao trabalhar com fotografia na área da Psicologia. O uso da fotografia pode servir como dispositivo para auxiliar as pessoas se expressarem verbalmente acerca de um tema, tornando mais fácil a compreensão do pesquisador. Em consonância a isso, para Maheirie et al. (2005), pode-se perceber e identificar informaçôes outras pelo uso da fotografia, de modo a introduzir novos conhecimentos (novas informações) às imagens primeiramente observadas. É um dispositivo capaz de gerar inquietações, questionamentos e reflexões, já que seu uso tem se tornado muito significativo (tanto em importância quanto em expansão) em pesquisa-intervenção, dando visibilidade a fenômenos que não seriam percebidos de outra maneira.

Neiva-Silva \& Koller (2002) identificaram quatro funções principais a respeito do uso das fotografias em pesquisas psicológicas. A primeira consiste na função de registro (documentar algo, o conteúdo da imagem é o foco, não importando o sujeito que a capturou). A segunda função é a modelo, em que as imagens são mostradas aos participantes e estes expressam suas impressões sobre elas; o foco, então, consiste no observador da fotografia. A terceira função é nomeada autofotográfica: os participantes são orientados a baterem fotos de acordo com alguma questão específica determinada pelo pesquisador e constitui-se como importante tanto o conteúdo das imagens quanto o sujeito que fotografa (assim como suas percepções a respeito de sua produção). Na última função, a fotografia é utilizada como ferramenta de feedback aos participantes. Geralmente, nessas pesquisas, as pessoas são avaliadas anteriormente em relação a algum aspecto pessoal, são fotografadas por outras pessoas e, posteriormente, apresenta-se o 
resultado à primeira. $\mathrm{O}$ autor da foto não é o foco, mas sim o efeito que esta produz no participante.

Maurente \& Tittoni (2007) realizaram um estudo com dois grupos de mulheres costureiras (um deles era ligado à economia solidária, e outro ligado a um programa de trabalho e geração de renda) em que utilizaram como estratégia metodológica a fotografia. Essas mulheres foram orientadas a fotografarem seu trabalho e, posteriormente, as imagens capturadas foram discutidas. Nessa experiência, as autoras identificaram a potencialidade da fotografia como método em pesquisa-intervenção em dois aspectos principais. O primeiro relaciona-se com a reflexão sobre o trabalho que o ato de fotografar proporcionou a esses dois grupos, já que a fotografia possibilita ao sujeito estranhar o familiar, observar o que antes não era visto (Strappazzon et al., 2008). Além disso, segundo Müller (2013), as imagens não são apenas vistas, estão sempre sendo revistas, e rever imagens é experiência de ser surpreendido com elementos que antes não eram o foco do olhar.

O segundo aspecto diz respeito à delimitação das imagens realizadas, ou seja, o que essas mulheres escolheram colocar ou não dentro do quadro da foto: "O que desejavam mostrar e aquilo que não queriam que fosse visto [...], de modo que a escolha sobre o que fotografar mostrava também o que era suportável ao olhar" (Maurente \& Tittoni, 2007, p. 35). Conforme Barros (2006), nas pesquisas em que se trabalha com fotografias, é necessário considerar que estas não são neutras, são construções mediadas pela subjetividade humana (do fotógrafo) e objetivadas em determinada materialidade a partir de certos recursos técnicos. Enfim, são produzidas pelo ser humano e nelas estão técnicas que organizam e direcionam nosso olhar (Titon, 2008).

Por meio dessas experiências, pode-se inferir que a fotografia apresenta a possibilidade de se constituir em uma importante ferramenta de intervenção, como dispositivo que pode atingir a expressão da fala dos sujeitos, facilitar reflexões e criações de novos conceitos sobre uma determinada questão, favorecer relações estéticas e sensibilizar o olhar, ressignificando percepções de mundo e criando novas ficções.

\section{MÉTODO}

Em princípio, objetivou-se fazer uma oficina de fotografia com uma temática focada na relação dos jovens com a cidade, pesquisar quais os possíveis recursos e limites que a cidade lhes proporcionava quanto às alternativas de lazer. A partir da participação de um fotógrafo profissional, o propósito inicial da oficina teve um enfoque maior na aprendizagem de técnicas de fotografia como possível 
recurso mediador para a sensibilização do olhar, possibilitando ainda eventuais perspectivas profissionais no trabalho com imagens, evitando, dessa forma, uma simples relação prático-utilitária com a linguagem fotográfica (Müller, 2013).

As temáticas abordadas na oficina constituíram-se de dois pilares fundamentais da fotografia: luz e composição. Discutiu-se sobre as diferenças entre fontes de luz e como a posição de um objeto em relação à luz pode modificar completamente uma imagem. Em relação à composição, algumas regras elementares de boas composições foram tratadas na oficina, como a identificação das linhas, das retas que constroem uma imagem. Vinculado a isso, foram analisadas as associaçôes emocionais e simbólicas que diferentes tipos de composição e proporção podem atribuir à fotografia.

Os responsáveis legais dos participantes assinaram um termo de consentimento livre e esclarecido (TCLE), o qual permitia que as fotos e as falas dos jovens pudessem ser utilizadas como material de pesquisa. Todos os procedimentos realizados durante os encontros foram registrados em um diário de campo, o qual serviu também como instrumento de análise. Outra ferramenta de registro foi uma máquina fotográfica utilizada somente para captar imagens dos jovens durante as atividades da oficina. Não se utilizou recursos de áudio e vídeo.

A oficina, na maioria de seus encontros, deu-se no espaço físico de uma escola estadual, localizada na cidade de Florianópolis, e referenciada no território do CRAS em que as alunas da graduação em Psicologia fizeram estágio. Intercorreram 11 encontros da oficina, em que se utilizou, além do espaço de duas escolas, de espaços públicos (realizou-se uma saída fotográfica) e o próprio espaço do CRAS. Os encontros ocorreram durante o período de setembro a novembro de 2013 , do qual fizeram parte 11 jovens entre 14 e 17 anos, que chegaram à oficina por meio de uma divulgação realizada nas escolas públicas (referenciadas no território do CRAS) e de uma mediação da equipe PAIF com uma família usuária do serviço. Além dos jovens e das estagiárias de Psicologia, também participaram da oficina um fotógrafo profissional, uma psicóloga e a equipe PAIF do CRAS. Os participantes usaram seus celulares para capturar as imagens e, durante os encontros e no passeio realizado, o fotógrafo disponibilizou uma câmera profissional, revezada pelos adolescentes.

No fim da oficina, as estagiárias elaboraram algumas perguntas aos jovens participantes, a fim de investigar quais os sentidos que eles atribuíram aos encontros realizados e as possíveis contribuições que a oficina lhes proporcionou (como perspectiva pessoal e profissional). Alguns jovens responderam a essas perguntas diretamente às estagiárias de Psicologia, que tomaram nota das respostas dadas, num modelo de entrevista aberta e com uma questão norteadora. 
Já outros jovens, que não compareceram ao último encontro, responderam às perguntas por meio da rede social.

Como estratégia de manter uma comunicação constante com os participantes e de compartilhar o material imagético produzido durante os encontros, foi criado um grupo na rede social Facebook. Como encerramento do projeto e forma de divulgação de oficinas de fotografia futuras, foi realizada uma exposição fotográfica no espaço da escola na qual ocorreu a maioria dos encontros.

O material de análise consistiu no conteúdo produzido por meio das respostas que os jovens deram às perguntas elaboradas pelas estagiárias, do discurso sobre as imagens fotográficas feitas durante os encontros e das informações obtidas do diário de campo, incluindo as informaçôes de redes sociais. Para análise das respostas dos participantes, trabalhamos com os discursos dos sujeitos, focando em conteúdos que se referem aos encontros da oficina antes e depois de sua realização, sobre as imagens produzidas, o olhar sob os trajetos percorridos no cotidiano e o olhar do outro sob suas fotografias. Ressalta-se, no entanto, que esses temas apresentam, entre si, atravessamentos, de forma que seu entrelaçamento é parte do conteúdo explorado neste artigo.

\section{DISCUSSÃO E RESULTADOS}

Os resultados aqui expostos são referentes à análise feita com base nas entrevistas realizadas com os participantes da oficina. As seis questóes respondidas pelos jovens buscavam explorar as expectativas deles antes do início das oficinas; a experiência durante os encontros e experiências que excediam o espaço do encontro; o compartilhamento das imagens com amigos e familiares, bem como a reação dessas pessoas em relação ao que foi produzido por eles; e sobre o olhar que tinham em relação às imagens por eles mesmos produzidas. Por conseguinte, configuraram-se os temas da análise sobre encontros da oficina antes e depois de sua realização; sobre as imagens produzidas; olhar sob os trajetos percorridos no cotidiano; olhar do outro sob suas fotografias.

No primeiro tema, chegamos à categoria "Os encontros com o outro", derivada dos encontros da oficina antes e depois de sua realização. Neste, havia como intenção explorar quais as impressóes que os jovens tinham acerca do que seria a oficina de fotografia e quais as possíveis ressignificações que deram à experiência de participação. Dentre as falas destacaram-se um interesse prévio pela construção das imagens (composição, movimento) e pelos seus usos; a oficina como oportunidade de conhecer novas pessoas; e participação a partir do incentivo de outros amigos. Das percepções que transcorreram por essas falas, observou-se que os participantes viam a oficina como espaço de possíveis 
encontros com outros colegas, por meio do qual ampliavam suas relações, em que puderam conhecer novas pessoas e, por mediação da fotografia, experienciar reciprocidades, tanto com as imagens quanto com os outros participantes e os oficineiros. Outro ponto de destaque foi o incentivo dado à participação na oficina pelo fato de outros colegas demonstrarem interesse de integrarem-se à oficina, fato que vai ao encontro da noção de pertencimento a um coletivo, sobre a qual dissertam Besset et al. (2008).

Como apontamentos ao fim da experiência, acentuam-se, nas falas dos jovens, significaçôes positivas à experiência de participar da oficina, como uma ressignificação dada às tardes de sexta-feira (dia dos encontros). Para eles, surge também uma oportunidade de "explorar um novo mundo [...], chances de explorar por dentro das máquinas, de expor ideias" [sic] por meio da fotografia. Nota-se, aqui, uma experiência de encontros prazerosos com outros sujeitos e, ao mesmo tempo, a experiência da aventura de conhecer, de explorar um novo objeto que produz matéria e significado na nova linguagem que se conquista. Salienta-se a subjetividade humana e sua capacidade de significação, na qual o sujeito pode se mostrar por meio da fotografia (Barros, 2006).

Em relação ao tema "Sobre as imagens produzidas", criamos a categoria "percepção da linguagem", derivada da investigação de possíveis diferenças nas percepções acerca das fotografias do início da oficina e fotografias do fim da oficina, e, então, compreendermos qual a relação que os sujeitos estabeleceram com suas próprias produçôes. Nesse sentido, sobressaíram-se falas que contemplavam importantes percepções acerca das diferenças quanto às imagens produzidas, principalmente no que diz respeito ao objeto, ao espaço a ser fotografado e ao autor das imagens. Outra questão importante quanto a algumas técnicas da fotografia foi o conhecimento que afirmaram ter adquirido em relação ao foco da fotografia e à composição da imagem. Os destaques acima disseram de uma ressignificação do olhar, ou seja, imagens que passaram a dizer aos participantes muito mais do que diziam antes, por meio de uma sensibilidade maior que eles concederam aos detalhes que construíam a imagem. Outrossim, uma valorização maior do que estava sendo fotografado: "Percebi muita diferença. Antes só apertava um simples botão e capturava a foto sem mais nem menos. Agora, eu percebo tudo ao redor" [sic]. Além disso, denotaram-se sentidos positivos ao que foi fotografado por eles. Outro fenômeno que apareceu nas falas foi um não reconhecimento prévio como autores das imagens, ou seja, houve certa surpresa em relação ao resultado produzido por eles próprios, um estranhamento com relação à autoria de seu próprio trabalho. Ao fim das oficinas, a experiência da apropriação de parte das técnicas da linguagem fotográfica possibilitou que se vissem como autores efetivos do que produziam, relatado por eles na entrevista final. 
Podemos nomear as experiências acima destacadas como uma ampliação estética que os sujeitos em questão puderam vivenciar por intermédio da fotografia, uma vez que contemplam a possibilidade criativa do sujeito, na qual se apresentou a alternativa de produzir novos sentidos sobre si próprio e sobre o território em que vivem. Esse aspecto foi identificado por meio do posicionamento dos jovens aos observarem o material produzido por eles mesmos, quando demonstraram uma grande satisfação ao se reconheceram autores fotógrafos daquelas imagens. Além disso, pelas respostas dadas às perguntas realizadas ao fim da oficina, identificou-se que, ao se reconhecerem como "fotógrafos", os jovens posteriormente também vislumbraram uma possibilidade de tornar a fotográfica uma atividade importante em suas vidas. Ou seja, na experiência de uma outra relação estabelecida com o mundo e consigo por meio das imagens, eles foram capazes de ressignificar, de se reconhecerem de modo diferente, indicando o fortalecimento de si como sujeitos.

O tema "Olhar sob os trajetos percorridos no cotidiano" visava a apurar quais as possíveis mudanças de percepções no caminho que percorriam no seu cotidiano, conhecer qual a relação que estabeleciam com o território. Desse tema surgiu a categoria "Olhares sobre o território". Foi utilizado, como exemplo norteador da entrevista, o trajeto percorrido de casa até a escola. Entre as falas dos sujeitos, salienta-se uma que contempla bastante o que foi observado nas outras falas:

Antes eu nem ligava para o que tinha ao meu redor, achava que era apenas uma rua, algumas ruas, mas depois eu comecei a olhar as coisas com outros olhos, percebi que, ao meu redor, havia mil maravilhas, que hoje sei aproveitar suas belezas, sei aproveitar o espaço por onde passo. Hoje em dia, aprecio muito as coisas $\left(\right.$ Tulipa $\left.^{6}\right)$.

Ou seja, uma fala que diz de transformaçõos nos modos de ver, na percepção do sujeito em relação a seu espaço, com um (re)conhecimento da potência que o território oferece como um universo de criação e de recriação de realidades previamente já impostas ao sujeito. Uma possibilidade de transformar, por meio do olhar, da fotografia, um espaço já consolidado. Segundo os princípios do CRAS (Crepop, 2008), contextualizar o sujeito no seu território e traçar quais as forças e os limites deste são recursos importantes dentro de uma estratégia de intervenção. Verifica-se que a fala acima transcrita convocou o sujeito a ressignificar os sentidos que ela dava a seu contexto, seu espaço de vivências cotidianas, em que pôde estabelecer uma relação privilegiada com ele. Por meio de uma relação que se fez ampliadora das configurações estéticas, o sujeito pôde

6 Os nomes originais foram modificados como forma de preservação da identidade dos participantes. 
aprimorar seu olhar e ressignificar seu modo de reconhecer os trajetos e objetos do cotidiano e, assim, recontextualizar seu território. Essa experiência vai ao encontro das observaçôes de Souza (2006), quando discute que a fotografia permite olhares outros que vão além do que um mero registro de espaço, pois exerce influências diretas nos registros da memória, o que, por conseguinte, remodela a relação do sujeito com o mundo.

Por fim, o tema "Olhar do outro sobre suas fotografias" visava a pesquisar o sentido que os jovens deram aos retornos recebidos de amigos ou de familiares quando lhes apresentaram as fotografias. No meio das falas, destacaram-se sentimentos de reconhecimento, por meio do elogio que receberam dos amigos e familiares. As expressões "senti-me orgulhosa de mim", "eles sentiram orgulho de mim" apareceram em quase todas as falas. Além disso, a atividade de sair para fotografar, de se encontrar com o grupo, surgiu em uma das falas como a possibilidade de ir além das ocupações mesmas do cotidiano, como uma oportunidade de experimentar o diferente, de conhecer cenários outros em que a vida acontece.

O sujeito se constitui na relação com o outro, a partir da dialética objetivosubjetivo, ou seja, uma constituição que pode ser ressignificada a todo tempo (Maheirie, 2002). Dessa forma, o convívio com o outro gera a possibilidade de o sujeito construir e rever o modo como se percebe no mundo, ressignificando os sentidos que dá a si mesmo. Na possibilidade de a oficina oferecer um espaço para a experiência do diferente, do inesperado, os bons encontros (Sawaia, 2001) aparecem como oportunidade de que a potência de existir (Spinoza, 2014) do sujeito seja aumentada, principalmente como espaço de convivência de um grupo de jovens (Besset et al., 2008). Vale ressaltar que, para Spinoza (2014), a potência de existir e de agir pode ser aumentada ou diminuída, dependendo dos encontros entre os corpos. Entendemos que essa experiência, por meio dos encontros entre os participantes e entre eles e a equipe que compóe as oficinas, pôde ter aumentado sua potência de existir, com base nos sentidos que produziram ao tecer os comentários sobre elas.

As entrevistas com os jovens participantes da oficina demonstraram que importantes foram as transformações percebidas por eles durante os encontros. Entre estas, evidenciaram-se mudanças quanto aos sentidos atribuídos às suas imagens produzidas no início e no fim dos encontros; mudanças em relação ao olhar sob os trajetos que percorrem no cotidiano, destacando-se uma maior sensibilidade aos componentes que compóem os cenários da vida desses jovens; e, por conseguinte, uma ressignificação dos jovens como sujeitos protagonistas de suas imagens, ressignificação dos sentidos que atribuem a eles próprios, a 
partir, principalmente, do reconhecimento, da visibilidade que puderam obter por meio da fotografia.

A evolução da qualidade das imagens dos participantes foi bastante significativa, principalmente em relação às imagens produzidas durante a saída de campo (em uma fortaleza da cidade de Florianópolis) e no encontro que se abordou a macrofotografia abstrata, quando os jovens se concentraram na beleza e na expressividade dos detalhes de objetos, como flores, canudos plásticos e garrafas de detergente.

No entanto também houve impasses e limites no contexto trabalhado. E, com o intento de melhorar as próximas oficinas, realizou-se uma conversa com a equipe PAIF, estagiárias, fotógrafo e psicóloga, com o objetivo de articular possíveis mudanças na realização, visando a torná-la ainda mais potencializadora. Durante a discussão, destacou-se que a principal dificuldade encontrada foi a assiduidade dos jovens nos encontros, pois, no total, 11 jovens estiveram presentes em algum encontro da oficina, no entanto somente um grupo de 6 permaneceu de forma regular até o fim dos encontros. Ressalta-se que, entre os jovens que não continuaram na oficina, alguns motivos relacionavam-se com atividades laborais ou com mudanças de bairro residencial, os quais dificultaram o acesso à oficina. Temos percebido que essa característica é recorrente nos trabalhos realizados em contextos dos CRAS. Como poderíamos enfrentar essa limitação? O que ela significa? Não temos como responder a essas questões neste artigo, mas estamos atentos a ela e pensamos que sua problematização é importante.

\section{CONSIDERAÇŌES FINAIS}

O CRAS configurou-se como um espaço mediador privilegiado para o oferecimento da oficina de fotografia, uma vez que consiste em uma instituição que visa ao fortalecimento dos vínculos comunitários, por meio, por exemplo, do propiciamento de espaços de convívio coletivo (nos quais os sujeitos puderam experienciar lugares outros na partilha do contexto social).

Uma importante estratégia de comunicação com os jovens foi o grupo criado na rede social Facebook, pois permitiu uma interação com eles durante o período em que não estávamos nos encontros da oficina, além de servir como espaço de compartilhamento de fotos.

Criar um espaço em que um grupo de jovens pôde interagir e refletir acerca de si e de seu território por intermédio da fotografia estruturou-se como um lugar favorável aos "bons encontros", em que se estabeleceram relações capazes de aumentar as potências de ação desses jovens, que passaram a se enxergar 
protagonistas de suas produções, vislumbrando perspectivas outras de si e de fazer no mundo.

A origem do SUAS, sancionado em 2004 por meio da PNAS, e, consequentemente, a criação e atuações dos CRAS são muito recentes no Brasil, o que fortalece a necessidade de um número maior de publicações científicas que venham a contribuir para a atuação do psicólogo no campo da Assistência Social.

Pensamos que novos projetos de pesquisa-intervenção com jovens e que venham a se realizar no contexto da proteção básica da Assistência Social possam ter um foco maior à estrutura dos encontros em espaços públicos do território, de modo que haja mais passeios coletivos no contexto da cidade. Tal prática lança o CRAS para fora de seu lugar, ampliando consideravelmente as estratégias para a construção e o fortalecimento de vínculos.

Ficam nossas questôes e certamente novos desafios nesta nova área, na qual nós precisamos também nos aventurar, desbravar e nos apropriar no campo inventivo do saber. 


\section{REFERÊNCIAS}

Alberto, M. de F. P., Freire, M. L., Leite, F. M. \& Gouveia, C. N. N. A. (2014). As Políticas públicas de Assistência Social e a atuação profissional. In I. F. de Oliveira \& O. H. Yamamoto (Orgs.), Psicologia e politicas sociais: temas em debate. (pp. 127-174). Belém: Ed. da UFPA.

Andrade, L. F. de \& Romagnoli, R. C. (2010). O psicólogo no CRAS: uma cartografia dos territórios subjetivos. Ciência e Profissão, 30(3), 604-619.

Barros, A. M. (2006). Fotografia e verbalidade frente ao (sur)real. In L. H. C. Lenzi, S. Z. Da Ros, A. M. A. Souza \& M. M. Gonçalves (Orgs.), Imagem: intervenção e pesquisa. (pp. 151-171). Florianópolis: Editora da UFSC.

Besset, V. L., Coutinho, L. G. \& Cohen, R. H. P. (2008). Pesquisa-intervenção com adolescentes: contribuições da psicanálise. In L. R. Castro \& V. L. Besset, Pesquisa-Intervenção na infância e juventude. (pp. 94-112). Rio de Janeiro: Trarepa/FAPERJ.

Brasil. Ministério do Desenvolvimento Social e Combate à Fome. (2005). Política Nacional de Assistência Social-PNAS 2004: Norma Operacional Básica : NOB/SUAS. Brasília: Ministério do Desenvolvimento Social e Combate à Fome.

Brasil. Ministério do Desenvolvimento Social e Combate à Fome. (2009). Orientaçôes técnicas: Centro de Referência de Assistência Social-CRAS. Brasília: Ministério do Desenvolvimento Social e Combate à Fome.

Brasil. Ministério do Desenvolvimento Social e Combate à Fome. (2012). Orientaçôestécnicassobreo PAIF(Vol. 1). Brasília:Ministério do Desenvolvimento Social e Combate à Fome.

Centro de Referência Técnica em Psicologia e Políticas públicas. (2008). Referência técnica para atuação do(a) psicólogo(a) no CRAS/SUAS. Brasília: Conselho Federal de Psicologia. Recuperado a partir de http://crepop.pol.org. br/novo/wpcontent/uploads/2010/11/referenciascras.pdf

Cruz, L. R. da \& Guareschi, N. (2009). Políticas públicas e assistência social. Petrópolis: Vozes.

Lei no 8.742, de 7 de dezembro de 1993. (1993, 7 dezembro). Lei Orgânica da Assistência Social. Dispõe sobre a organização da Assistência Social e dá outras providências. Brasília: Portal da Legislação. Recuperado a partir de http:// 
www.planalto.gov.br/ccivil_03/leis/18742.htm

Maheirie, K. (2002). Constituição do sujeito, subjetividade e identidade. Revista Interaçôes, 7(13), 31-44.

Maheirie, K., Boing, P. \& Pinto, G. C. (2005). Pesquisa e intervenção por meio da imagem: o recurso fotográfico no cotidiano de varredores de rua. Psico, 36(2), 213-219.

Maheirie, K., Hinkel, J., Groff, A. R., Müller, F. L., Gomes, M. de A. \& Gomes, A. H. (2012). Coletivos e relações estéticas: alguns apontamentos acerca da participação política. In L. R. de Castro, C. Mayorga \& M. A. M. Prado. (Orgs.), Juventude e a experiência do politico no contemporâneo. (pp. 143-167). Rio de Janeiro: Contracapa.

Maheirie, K., Müller, F. L., Gomes, M. A., Gomes, A. H. \& Hinkel, J. (2011). Formaçôes conectivas e coletivas em fotografia: pensando a política na esfera da estética. In A. V. Zanella \& J. Tittoni (Orgs.), Imagens no pesquisar: experimentaçôes. (pp. 227-247). Porto Alegre: Dom Quixote.

Maurente, V. \& Tittoni, J. (2007). Imagens como estratégia metodológica em pesquisa: a fotocomposição e outros caminhos possíveis. Psicologia \& Sociedade, 19(3), 33-38.

Müller, F. L. B. (2013). A cidade em foco: olhares a partir do bairro Chico Mendes. (Dissertação de Mestrado). Universidade Federal de Santa Catarina, Programa de Pós-Graduação em Psicologia, Florianópolis.

Neiva-Silva, L. \& Koller, S. H. (2002). O uso da fotografia na pesquisa em Psicologia. Estudos de Psicologia, 7(2), 237-250.

Oliveira, I. F., Dantas, C. M. B., Sólon, A. F. A. C \& Amorim, K. M. O. A. (2011). Prática psicológica na proteção social básica do SUAS. (Número Especial). Psicologia \& Sociedade, 23, 140-149.

Pino, A. (2006). Imagem, mídia e significação. In L. H. C. Lenzi, S. Z. Da Ros, A. M. A. Souza \& M. M. Gonçalves (Orgs.), Imagem: intervenção e pesquisa. (pp. 51-62). Florianópolis: Editora da UFSC.

Reis, R. G. \& Cabreira, L. (2013). As políticas públicas e o campo: e o psicólogo com isso? (Número Especial). Ciência e Profissão, 33, 54-65.

Sawaia, B. B. (2001). O sofrimento ético político como categoria de análise da 
dialética exclusão/inclusão. In B. B. Sawaia. As artimanhas da exclusão: análise psicossocial e ética da desigualdade social. (pp. 97-118). Petrópolis: Vozes.

Senra, C. M. G. \& Guzzo, R. S. L. (2012). Assistência social e psicologia: sobre as tensōes e conflitos do psicólogo no cotidiano do serviço público. Psicologia \& Sociedade, 24(2), 293-299.

Silva, J. V. \& Corgozinho, J. P. (2011). Atuação do psicólogo, SUAS/CRAS e Psicologia Social Comunitária: possíveis articulações. (Número Especial). Psicologia e Sociedade, 23, 12-21.

Souza, P. (2006). A foto como modo de intervenção. In L. H. C. Lenzi, S. Z. Da Ros, A. M. A. Souza \& M. M. Gonçalves (Orgs.), Imagem: intervenção e pesquisa. (pp. 121-138). Florianópolis: Editora da UFSC.

Spinoza, B. de (2014). Ética. (T. Tadeu, Trad.), Belo Horizonte: Autêntica.

Strappazzon, A. L. (2011). Bons encontros: relaçôes éticas e estéticas na Casa Chico Mendes. (Dissertação de Mestrado), Universidade Federal de Santa Catarina, Programa de Pós-Graduação em Psicologia, Florianópolis.

Strappazzon, A., Santa, B., Werner, F. W. \& Maheirie, K. (2008). A criação fotográfica e o aumento da potência de ação: experiências e possibilidades. Cadernos de Psicopedagogia, 7(12). Recuperado a partir de http://pepsic. bvsalud.org/scielo.php?script=sci_arttext\&pid=S1676-10492008000100002

Titon, A. P. (2008). Jovens de baixa renda de Florianópolis/SC e suas relaçôes na e com a cidade. (Dissertação de Mestrado), Universidade Federal de Santa Catarina, Programa de Pós-Graduação em Psicologia, Florianópolis.

Vigotsky, L. S. (2003). Imaginación y creación en la edad infantil. Buenos Aires: Nuestra América.

Yamamoto, O. H. \& Oliveira, I. F. (2014). Definindo o campo de estudo: as políticas Sociais Brasileiras. In I. F. de Oliveira \& O. H. Yamamoto (Orgs.), Psicologia e políticas sociais: temas em debate. (pp. 21-45). Belém: Editora da UFPA.

Zanella, A. V. (2010). Psicologia social... Arte... Relações estéticas... Processos de criação...: fios de uma trajetória de pesquisa e alguns de seus movimentos. In A. V. Zanella \& K. Maheirie (Orgs.), Diálogos em Psicologia social e Arte. (pp. 29-38). Curitiba: CRV. 
Zanella, A. V., Cabral, M. G., Maheirie, K., Da Ros, S. Z., Urnau, L. C., Titon, A. P., Sander, L. (2006). Relações estéticas, atividade criadora e constituição do sujeito: algumas reflexões sobre a formação de professores(as). Cadernos de Psicopedagogia, 6(10).

Zanella, A. V. \& Tittoni, J. (2011). Imagens no pesquisar: experimentaçôes. Porto Alegre: Quixote. 